\title{
Magnetic/Polyetherimide-Acrylonitrile Composite Nanofibers for Nickel Ions Removal from Aqueous Solution
}

\author{
Muhammad Omer Aijaz ${ }^{1}$, Mohammad Rezaul Karim ${ }^{1,2, *}$, Hamad F. Alharbi ${ }^{3}$, Nabeel H.
}

Alharthi $^{3}$, and Fahad S. Al-Mubaddel ${ }^{2,4}$

${ }^{1}$ Center of Excellence for Research in Engineering Materials (CEREM), Deanship of Scientific Research (DSR), King Saud University, PO Box 800, Riyadh 11421, Kingdom of Saudi Arabia, ${ }^{2}$ K.A.CARE Energy Research and Innovation Center, Riyadh 11451, Kingdom of Saudi Arabia, ${ }^{3}$ Mechanical Engineering Department, King Saud University, PO Box 800, Riyadh 11421, Kingdom of Saudi Arabia, and

${ }^{4}$ Chemical Engineering Department, King Saud University, PO Box 800, Riyadh 11421, Kingdom of Saudi Arabia,

\begin{abstract}
Within the study, magnetic/polyetherimide-acrylonitrile composite nanofibers membrane with effective adsorption of nickel ions in aqueous solution were established, through a simple electrospinning method. Iron oxide nanoparticles were stirred and ultrasonically dispersed into polyetherimide-acrylonitrile solution for homogenous suspension. Afterwards, the polyetherimide-acrylonitrile solution with uniform suspension of iron nanoparticles was used in electrospinning machine to produce uniform and smooth nanofibers composite membrane. The confirmation of nanoparticles incorporation into polymeric membrane were characterized by SEM, EDX, FTIR, XRD and nanoparticles aqueous stability through leach out test. The high adsorption capability of the composite membranes on nickel ions was mainly attributed to the combination of magnetic nanoparticles, polyetherimide-acrylonitrile matrix and nano-sized structure of membrane. Membrane containing magnetic nanoparticles demonstrate the maximum adsorption capabilities $(102 \mathrm{mg} / \mathrm{g})$ for nickel ions from aqueous solution. Different kinetics and isotherm
\end{abstract}


models were applied to understand the adsorption behavior during adsorption process, amongst them pseudo second order kinetic and Langmuir isotherm model were well fitted. Additionally, EDX, FTIR and XRD results confirmed the presence of nickel ions onto membrane after adsorption process. Polyetherimide-acrylonitrile composite nanofibers membranes containing magnetic nanoparticles may use as an environmentally-friendly and non-toxic adsorbent for the removal of nickel ions in aqueous medium due to its ease of preparation, easy to use and stability in aqueous medium by retaining the nanoparticles inside the nanofibers membranes.

Keywords: Polyetherimide; polyacrylonitrile; nanofiber membranes; magnetic nanoparticles; nickel ions.

*Corresponding author. e-mail address: mkarim@ksu.edu.sa (M. R. Karim).

\section{INTRODUCTION}

Metal ions is one of the major source to contaminate the water resource and creating problems in environmental ecosystem. Nickel ions $\left(\mathrm{Ni}^{2+}\right)$ is one of the common environmental toxicant pollutant that widely produced from different industries such as lead frame, electroplating, tableware, plastics manufacturing, fertilizers, nickel base batteries, pigments, metal finishing, connecter, mining and metallurgical operations. Nickel known as a carcinogen because ingestion of nickel in higher concentration create many health problems such as damage to kidneys, lungs and stomach problem, e.g. vomiting, diarrhea, renal edema, skin dermatitis, nausea and pulmonary fibrosis [1-3].

To concern this issue, many efforts have been devoted to developed the effective and inexpensive method to remove $\left(\mathrm{Ni}^{2+}\right)$, for the treatment of metal ions from water resource many methods applied such as chemical precipitation, ion-exchange, solvent extraction, reverse osmosis, 
filtration, evaporation and adsorption [4-6]. Removal of metal ions from water through adsorption method has been widely used due to its low cost, ease of operation, better efficiency and low further pollutant [7-9]. To adsorb the pollutant many adsorbents have been successfully used such as biomaterials, carbon materials, metal oxide nanoparticles and nano fibrous membranes. Nanofibers membranes attracts more attention among other adsorbents due to high specific area and porosities that allow nanofibers membranes to capture more metal ions on its free sites [1013]. Electrospining method has the ability to produces different compositions of electrospun nanofibers with enormous surface area, high porosity and gas permeability $[14,15]$.

Polyacrylonitrile (PAN), is a semi crystalline synthetic polymer with tremendous ability to form nanofibers sheet with chemical stability $[16,17]$. PAN has the capability to produce many products such as ultra-filtration mats, hollow fibers for reverse osmosis, and fibers for textiles. PAN tends to swell and plasticize in aqueous medium due to good hydrophilicity [18]. To overcome this problem an amorphous material (Polyetherimide (PEI)) having excellent filmforming ability in addition with relatively better thermal, mechanical, chemical stability were introduced. Successful blending of PEI and PAN not only improved the smoothness of nanofibers membranes but also improve thermal property of PAN [19].

Inorganic nanoparticles adsorbents are another suitable material for removal of heavy metals from the aqueous system [20-23] but easy to agglomerate in aqueous medium and difficult to recycle. Iron oxide nanoparticle is more attractive to use as an absorbent due to its important features such as small size, high surface to volume ration and magnetic property [24-29]. Therefore, mixing magnetic nanoparticles with electrospun polymeric nanofibers can overcome the agglomeration and recycling problem, hence used as an efficient adsorbent for the removal of heavy metal ions [30-32]. 
In present study, magnetic/polyetherimide-acrylonitrile composite electrospun nanofibers membranes with high surface area were prepared for the removal of $\left(\mathrm{Ni}^{2+}\right)$ ions. To find out the suitable conditions for adsorption study different adsorption conditions were investigated such as $\mathrm{pH}$, time and initial concentration. Furthermore, isotherms, kinetic models, EDX, FTIR, XRD and BET investigations were applied to explored the adsorption mechanism of composite membrane.

\section{EXPERIMENTATIONS}

\section{Materials and suppliers}

(a) Membrane core materials; Polyacrylonitrile (PAN (MW =150,000)), Polyetherimide (PEI (Ultem ${ }^{\mathrm{TM}}$ resin 1000)) and magnetic nanoparticles (Iron oxide $\left(\mathrm{Fe}_{2} \mathrm{O}_{3}\right.$ (Sigma Aldrich))) (b) solvent for electrospinning solution N, N-Dimethylformamide (DMF (Sigma Aldrich)), (c) to adjust pH; hydrochloric acid ( $\mathrm{HCl}$ (Sigma Aldrich) and sodium hydroxide ( $\mathrm{NaOH}$ (Sigma Aldrich)) and (d) metal ions for adsorption study, nickel (II) (acetate tetrahydrate $\left(\mathrm{C}_{4} \mathrm{H}_{14} \mathrm{NiO}_{8}\right.$ (sigma Aldrich)). Chemicals were analytical grade and no modification were performed prior to use.

\section{Solutions for Electrospinning Machine}

To prepare the homogenous PEI and PAN solution, 2\% and $10 \%$ of PEI and PAN were added into DMF solvent separately and stirrer for $60 \mathrm{~min}$ at 80 and room temp, respectively. Afterward, PEI and PAN solutions were mixed homogenously together at 3:1 ratio using magnetic stirrer at 80 degrees for $60 \mathrm{~min}$ and named PEI-AN solution. After $60 \mathrm{~min}$ of mixing, $2 \%$ iron oxide was introduced by maintaining the temperature at $80 \mathrm{C}$ for $30 \mathrm{~min}$. To improve magnetic nanoparticles dispersion and remove bubbles from solution, $60 \mathrm{~min}$ of sonication were performed and named Fe/PEI-AN solution. 


\section{Production of Electrospun Nanofibers}

Now, PEI-AN and Fe/PEI-AN solutions were used to produce nanofibers through electrospinning system with 30kV max capacity of electrospinning machine (MECC, Japan; model NF-500). Fill up the $10 \mathrm{ml}$ syringe with needle diameter of $0.6 \mathrm{~mm}$ with PEI-AN and Fe/PEI-AN solution separately and syringe attached with pump assemble while needle connected to high voltage supply (scheme1). The optimized electrospinning parameters were used reported in previous study [19]. Briefly, applied voltage $19 \mathrm{kV}$, flowrate $0.6 \mathrm{ml} / \mathrm{hr}$, collector to needle distance $15 \mathrm{~cm}$, humidity $20 \%$. After collecting the nanofibers membranes from drum collector, the membranes were placed in over drier at 60C for $24 \mathrm{hr}$ and composite membranes labelled as PEI-AN for polyetherimideacrylonitrile nanofibers membrane and Fe/PEI-AN for polyetherimide-acrylonitrile with magnetic particle $\left(\mathrm{Fe}_{2} \mathrm{O}_{3}\right)$ nanofibers membrane.

\section{CHARACTERIZATIONS}

\section{Morphological Study}

The morphologies of PEI-AN and Fe/PEI-AN nanofibers membranes were done using field emission scanning electron microscope (FE-SEM (JSM-7600, JEOL Japan)). In FE-SEM chamber, small piece of nanofibers membranes sputtered with a layer of platinum for 60s under vacuum were used. The average diameter of 50 individual fibers were calculated through the JSM7600 software.

\section{Infrared Spectra analyses}

The Fourier transformed infrared (FT-IR) (VERTEX-70, Bruker) was used in the range of 600 $4000 \mathrm{~cm}^{-1}$ to identify the functional groups of Fe/PEI-AN and PEI-AN. 


\section{X-ray diffraction}

X-Ray diffraction (XRD) (D8 Discover, Bruker) measurements were carried out on PEI-AN and Fe/PEI-AN nanofibers membranes to confirm the membranes compositions and metal ions attachment on composite membranes before and after adsorption study. The XRD test conducted under the lamp of $\mathrm{Cu} \mathrm{K \alpha}$ operated at $40 \mathrm{kV} / 40 \mathrm{~mA}$ in the angle range between 5-100 degree with the scanning speed of 2 degrees per minute.

\section{Surface Area Measurements (BET)}

The specific surface area, pore diameter and pore volume of composite nanofibers membranes were measured by a surface area and pore volume analysis (Brunauer, Emmett and Teller (BET) FlowPrep-060, Micromeritics Instrument Corp. USA).

\section{Adsorption study}

The stock solution of $\mathrm{Ni}^{2+}$ for adsorption study was prepared by adding $0.42 \mathrm{~g} \mathrm{of}_{6} \mathrm{H}_{14} \mathrm{NiO}_{8}$ into $1000 \mathrm{ml}$ deionized water. For adsorption studies, certain amount of nanofibers membranes were immersed in $\mathrm{Ni}^{2+}$ containing solution and shaken at $25^{\circ} \mathrm{C}$. Final $\mathrm{Ni}^{2+}$ solution concentration after adsorption studies were measured by AAs and adsorption capacities of metal ions were calculated using below equation.

$$
Q=\frac{C_{0}-C_{e}}{M} * V
$$

Where $\mathrm{Q}$ is the amount of metal ions adsorb in mille gram $(\mathrm{mg} / \mathrm{g}), C_{0} \& C_{e}$ was the initial and final concentration, respectively in part per million ( $\mathrm{ppm}), \mathrm{V}$ was the metal ion solution volume in Liter (L) and $\mathrm{M}$ was the mass of adsorbent used in gram (g). Reported adsorption data were the average of triplet values calculated under same parameters. 
To study the influence of $\mathrm{pH}$ (2-8), time (1-180min) and concentration(50-450ppm) values on the adsorption of $\mathrm{Ni}^{2+}$, approximately $12 \mathrm{mg}$ of nanofibers membranes were added into $10 \mathrm{ml}$ of $\mathrm{Ni}^{2+}$ solution under shaking at 400rpm. The $\mathrm{pH}$ values were adjusted using $0.5 \mathrm{HCl}$ and 0.5 $\mathrm{NaOH}$, effects of $\mathrm{pH}$ at higher values were not recorded due to the precipitations of metal hydroxide [33-35].

\section{DISCUSSION OF OUTCOMES}

\section{Morphological Study}

Figure 1 shows the morphological and digital evidences of prepared nanofibers membranes with or without magnetic particles. Figure 1(a) showed the smooth, bead and drop-less fine fibers of PEI-AN nanofibers with average diameter of $230 \mathrm{~nm}$, the zoom-in image showed stable fibers with some wrinkled and creased surface that could help in seizing metal ions. Figure 1(b) shows the morphological SEM images of Fe/PEI-AN membrane, where iron particles fused with fiber can easily be seen. Energy dispersive X-ray spectroscopy (EDX) results further confirmed the presence of iron $(1.7 \%)$ in nanofibers showed in figure (c). Digital images of prepared illustrated in figure 1(d), the dark color of membrane also confirms the addition of $\mathrm{Fe}_{2} \mathrm{O}_{3}$ in $\mathrm{Fe} / \mathrm{PEI}-\mathrm{AN}$ membrane. 

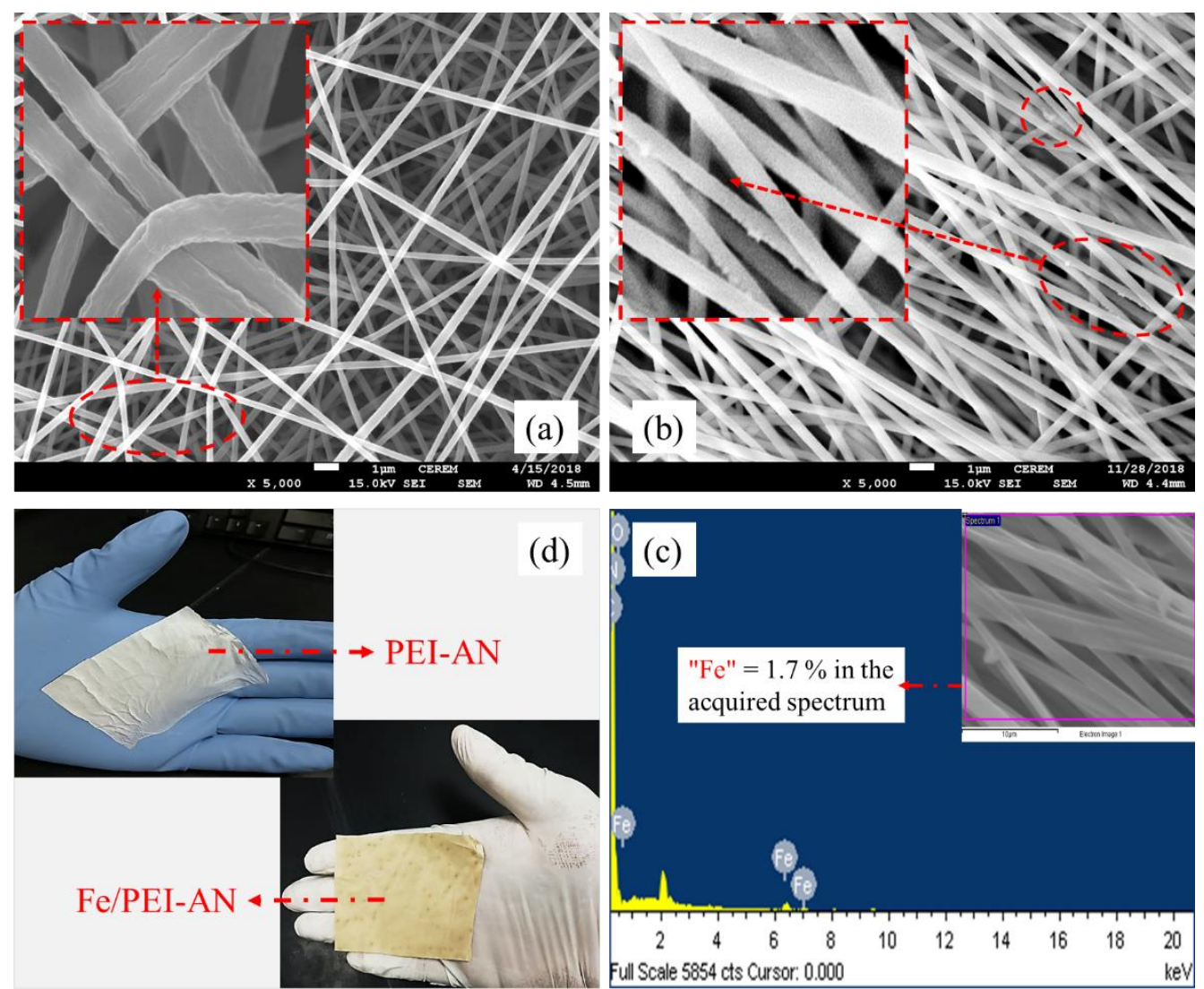

Figure 1. SEM \& EDX images of prepared composite nanofibers membranes (a) PEI-AN, (b)

Fe/PEI-AN, (c) EDX of Fe/PEI-AN \& (d) Digital images of prepared membranes.

\section{Leaching test of magnetic particles}

In order to investigate the stability of magnetic nanoparticles in Fe/PEI-AN composites nanofibers. The 30mg of Fe/PEI-AN was added in $25 \mathrm{ml}$ of distilled water for 60 hours at 400rpm. To test the nanoparticles traces leached out in water was measured using inductivity coupled plasma optical emission spectrophotometer (ICP-OES, PerkinElmer Optima 4300 DV, USA). There were no traces found in water that confirmed the good incorporation of iron oxide particle in Fe/PEI-AN membrane. Therefore, composite nanofibers membrane containing magnetic particle can be used as efficient material for sorption of metal ions with no further contamination. 


\section{Infrared Spectra analyses}

Figure 2 shows the ATR-FTIR spectral curves to investigate the chemical structure of PEI-AN and Fe/PEI-AN nanofibers membranes. The presence of PEI and PAN in both the curves were confirmed by the characteristic nitrile group $(\mathrm{C} \equiv \mathrm{N})$ of PAN at $2245 \mathrm{~cm}^{-1}$ and imide group (R-CON-CO-R') of PEI at $1774 \mathrm{~cm}^{-1}$ and $1721 \mathrm{~cm}^{-1}$ [19]. The presence of iron oxide in Fe/PEI-AN nanofibers was further confirmed by the characteristic peak at $575 \mathrm{~cm}^{-1}$ that attribute the stretching vibrations $(\mathrm{Fe}-\mathrm{O})$ of iron oxide nanoparticles [36]. All the identical peaks confirmed the presence of PEI, PAN and magnetic nanoparticles in the membrane's composition.

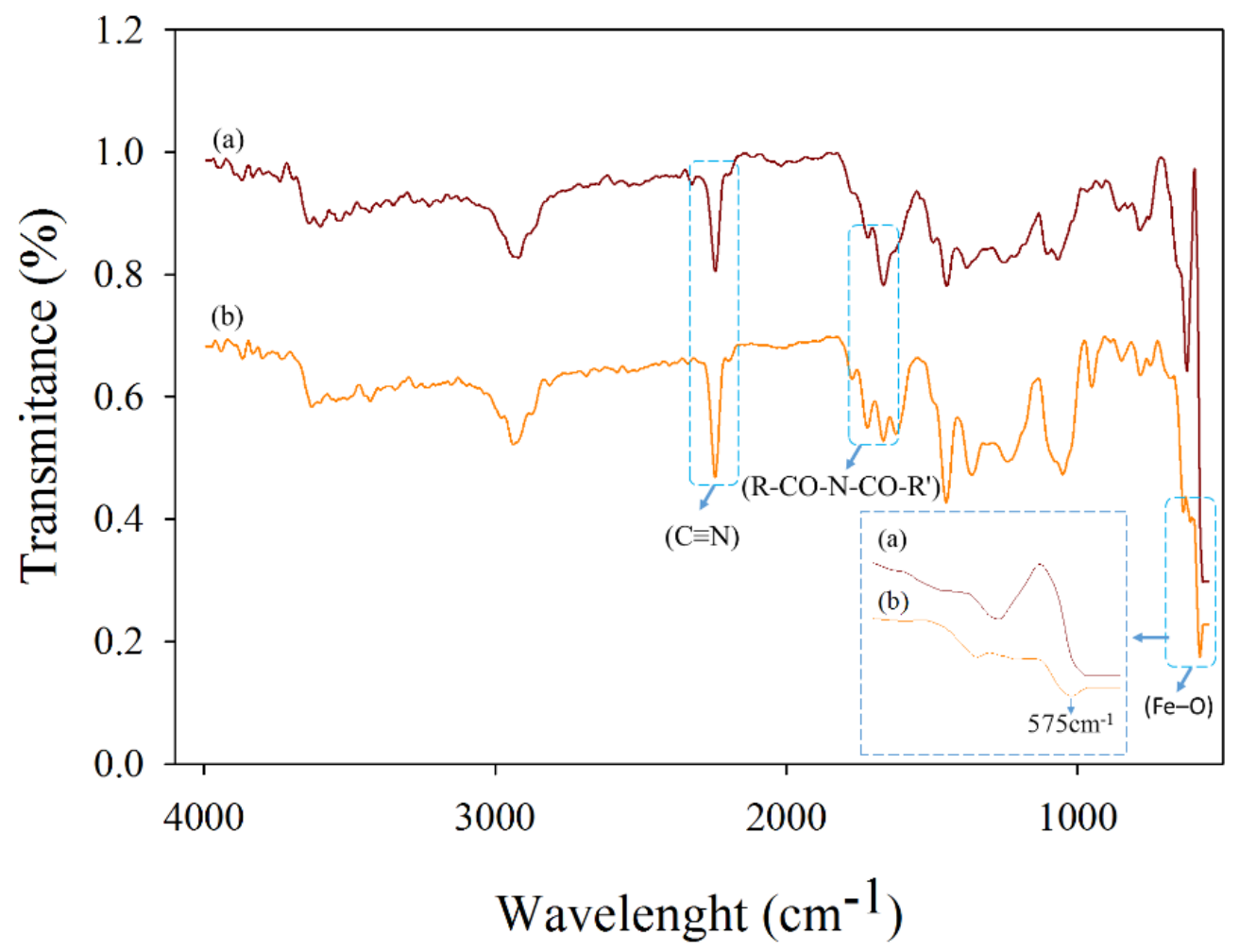

Figure 2. ATR-FTIR curves of composite nanofibers membranes (a) PEI-AN \& (b) Fe/PEI-AN.

\section{X-ray diffraction}

X-ray diffractograms of PEI-AN and Fe/PEI-AN are shown in figure 3. In figure 3(a) two typical crystalline peaks of PAN appeared at $16.6^{\circ}$ and $29.2^{\circ}$, reflects the linear structure of PAN. No peaks were recorded for PEI because of amorphous in nature. Figure 3(b) presented the diffraction 
peaks related to iron oxide at $35.7,43.34,53.8,57.1$ and $62.8^{\circ}$. These attributed peaks further confirmed the presence of magnetic nanoparticles in the composite nanofibers membranes.

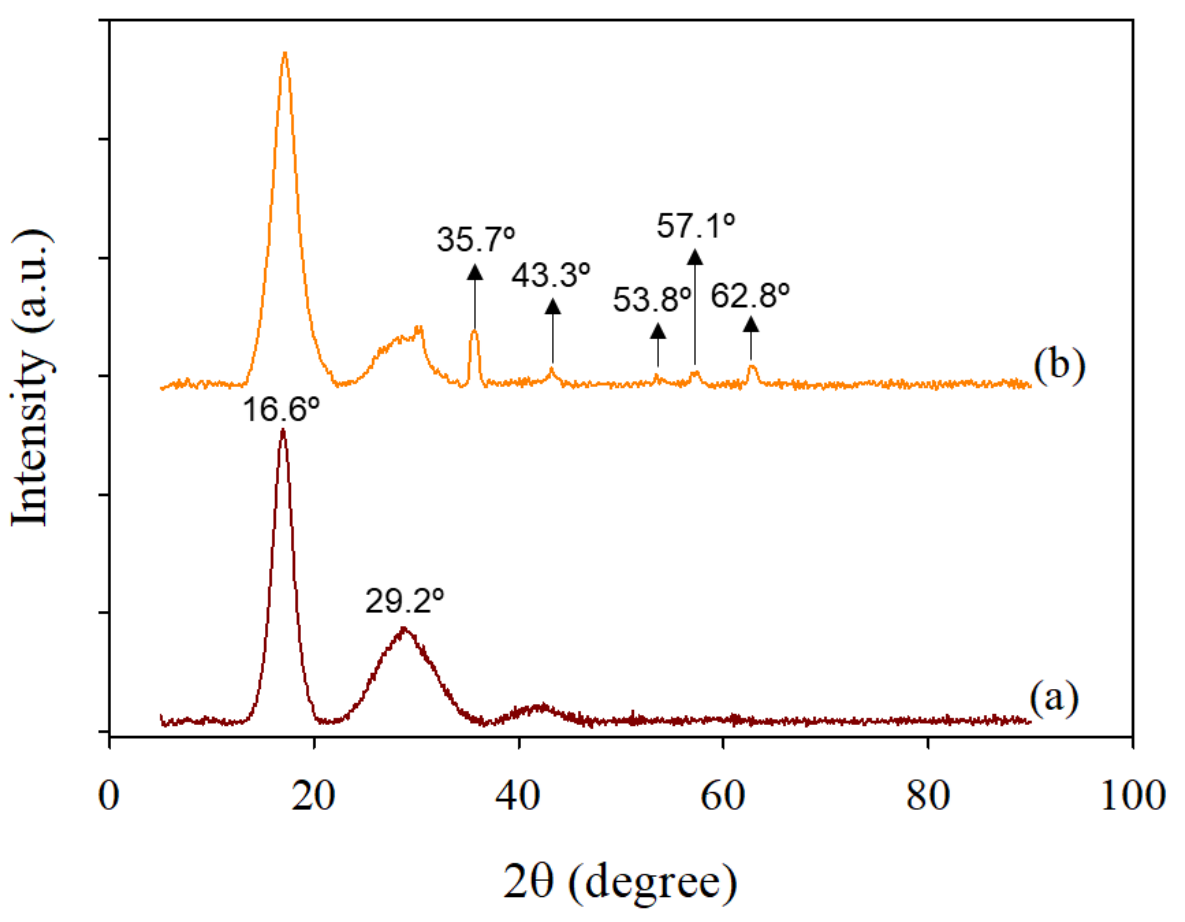

Figure 3. XRD results of composite nanofibers membranes (a) PEI-AN \& (b) Fe/PEI-AN.

\section{Metal ions adsorption study}

To find out the maximum adsorption capacity, stepwise effects of different conditions such as, $\mathrm{pH}$ values, time interval and initial concentration studies were conducted. Adsorption of prepared membranes for $\mathrm{Ni}^{2+}$ were firstly measure on the basis of $\mathrm{pH}$ values ranging from 2-8. Experiments were performed using $10 \mathrm{ml}$ initial $\mathrm{Ni}^{2+}$ concentration of $25 \mathrm{mg} / \mathrm{L}$ and $12 \mathrm{mg}$ of PEI-AN and Fe/PEI-AN nanofibers at room temperature. Figure 4(a) shows the removal percentage of $\mathrm{Ni}^{2+}$ in the $\mathrm{pH}$ range of 2-8. The adsorption percentage increased with increasing $\mathrm{pH}$ and reached highest values at approximately $8 \mathrm{pH}$. Lower adsorption percentages were observed at lower $\mathrm{pH}$ values due to the formation of $\mathrm{H}^{+}$that covered the metal ions [37,38]. The PEI-AN and Fe/PEI-AN were shown the maximum adsorption efficiency of $\mathrm{Ni}^{2+}$ at $8 \mathrm{pH}$ that were 83 and $91 \%$, respectively. 
Figure 4(b) shows the effect of adsorption time on the adsorption capacity of PEI-AN and Fe/PEI-AN membranes. The time study was carried out using $10 \mathrm{ml}$ of initial $\mathrm{Ni}^{2+}$ concentration of $25 \mathrm{mg} / \mathrm{L}$ and $12 \mathrm{mg}$ of PEI-AN and Fe/PEI-AN at $8 \mathrm{pH}$ for $1-180 \mathrm{~min}$. The adsorption capacity sharply increased as time increased till 30min. After 30min, adsorption growth rate gradually decreased and reached to the adsorption equilibrium at 60min. Sharply increased in adsorption (till 30min) might be due to the availability of free sites, more surface area and porosities of nanofibers adsorbents. The adsorption after 30min showed the decreased growth rate of adsorption capacity with further increase in contact time until the adsorption equilibrium reached. This phenomenon was due to the limited availability of adsorptive sites and metal ions concentration. Similar effect of time on adsorption were seen for both the membranes but iron containing membrane showed higher adsorption capacity. This might due to the presence of iron particle that enhanced the specific surface area and adsorption sites.
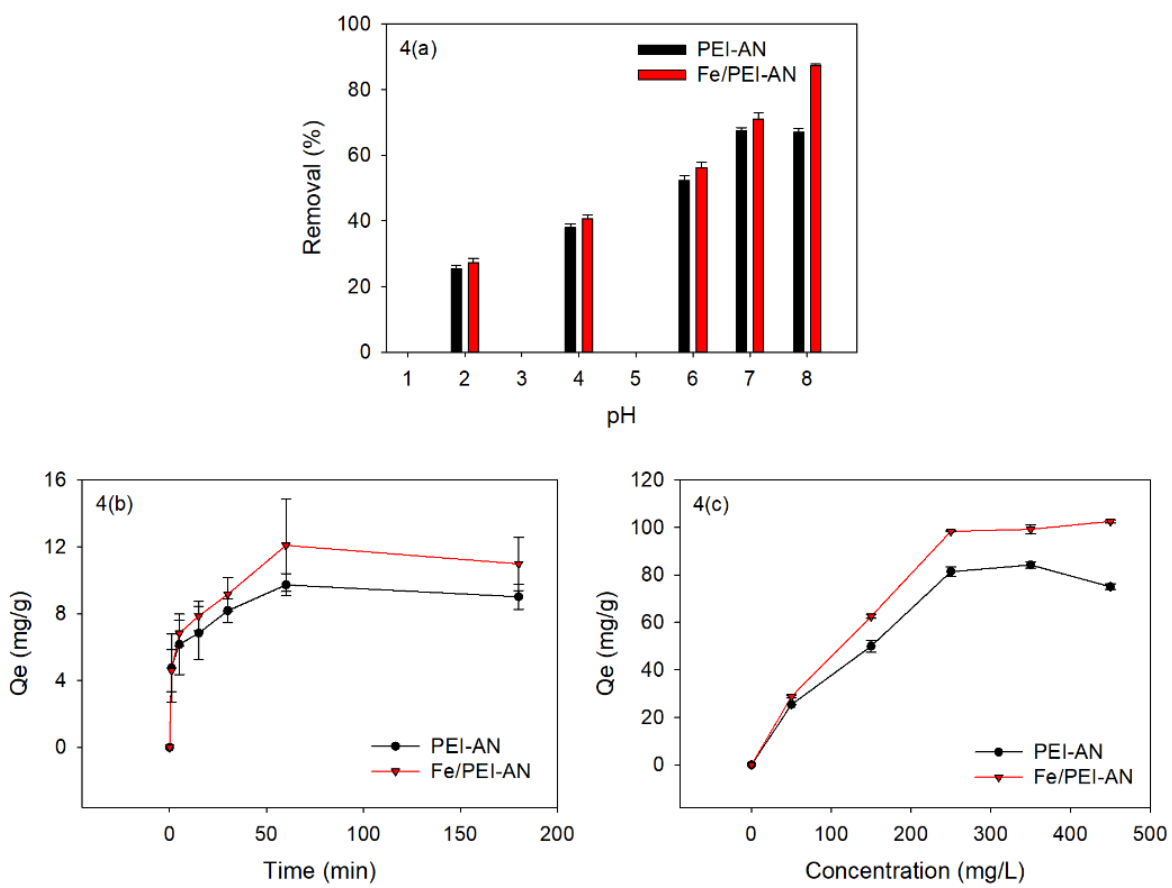

Figure 4. Effect of different conditions on $\mathrm{Ni}^{2+}$ adsorption study for composite nanofibers membranes (a) pH study, (b) Time study \& (c) initial concentration study 
Figure 4(c) shows the effect of initial concentration of the adsorption of $\mathrm{Ni}^{2+}$ onto PEI-AN and Fe/PEI-AN nanofibers membranes. For concentration experiments, $10 \mathrm{ml}$ of initial $\mathrm{Ni}^{2+}$ concentrations $(50-450 \mathrm{mg} / \mathrm{L})$ and $12 \mathrm{mg}$ of nanofibers adsorbent were used to find out the maximum adsorption of metal ions at $8 \mathrm{pH}$ and $60 \mathrm{~min}$. As the initial concentration of $\mathrm{Ni}^{2+}$ increased, the amount of adsorption capacity improved gradually, specially Fe/PEI-AN exhibits higher $\mathrm{Ni}^{2+}$ adsorption capacity than PEI-AN. Better adsorption of Fe/PEI-AN was due to the availability of more adsorption sites for $\mathrm{Ni}^{2+}$ provided by nanoparticle inside the membrane [39]. The amount of adsorption capacity was increased sharply as the initial concentration changed from 50 to $250 \mathrm{mg} / \mathrm{L}$. After $250 \mathrm{mg} / \mathrm{L}$ of initial concentration, the adsorption tendency became slow and reached maximum value of $\sim 84$ and $\sim 102 \mathrm{mg} / \mathrm{g}$ when the initial concentration was 350 and $450 \mathrm{mg} / \mathrm{l}$, respectively.

\section{Kinetics and isotherm models for adsorption study}

To better explore the adsorption mechanism onto membranes during process of adsorption, various kinetic models were applied such as, pseudo-first-order, pseudo-second-order, Elovich, power function, and intraparticle diffusion. To determine the closeness between the experimental and model predicted adsorption data, the standard error of estimate (SEE) and the coefficient of determination $\left(\mathrm{R}^{2}\right)$ were calculated. Linear expressions of above-mentioned kinetics and estimations expressed in table 1 and table 2, respectively.

Table1 List of adsorption Kinetic \& isotherm models

\begin{tabular}{|c|c|c|c|}
\hline \multicolumn{4}{|c|}{ Kinetic Models* } \\
\hline Model & Equation & Plot & Reference \\
\hline $\begin{array}{l}\text { Pseudo-First-Order } \\
\text { (PFO) }\end{array}$ & $\ln \left(Q_{e}-Q_{t}\right)=\ln Q_{e}-\frac{k_{1}}{2.303} t$ & $\ln \left(Q_{e}-Q_{t}\right) v s t$ & [40] \\
\hline $\begin{array}{l}\text { Pseudo-Second- } \\
\text { Order (PSO) }\end{array}$ & $t / Q_{t}=1 / k_{2} Q_{e}^{2}+t / Q_{e}$ & ${ }^{t} / Q_{t} v s t$ & [40] \\
\hline
\end{tabular}




\begin{tabular}{|c|c|c|c|}
\hline Elovich & $Q_{t}=\frac{\ln (\alpha \beta)}{\beta}+\frac{\ln t}{\beta}$ & $Q_{t} v s \ln t$ & {$[41]$} \\
\hline Power Function & $\ln Q_{t}=\ln b+\mathrm{k}_{f} \ln t$ & $\ln Q_{t} v s \ln t$ & {$[42]$} \\
\hline $\begin{array}{c}\text { Intraparticle } \\
\text { Diffusion }\end{array}$ & $Q_{t}=\mathrm{c}+\mathrm{k}_{i d} \mathrm{t}^{0.5}$ & $Q_{t} v s \mathrm{t}^{0.5}$ & {$[38]$} \\
\hline
\end{tabular}

\section{Isotherm Models ${ }^{* *}$}

\begin{tabular}{|c|c|c|c|}
\hline Langmuir & $\frac{\mathrm{C}_{\mathrm{e}}}{\mathrm{Q}_{\mathrm{ec}}}=\frac{1}{\mathrm{Q}_{\mathrm{m}} \mathrm{K}_{\mathrm{L}}}+\frac{\mathrm{C}_{\mathrm{e}}}{\mathrm{Q}_{\mathrm{m}}}$ & $\frac{\mathrm{C}_{\mathrm{e}}}{\mathrm{Q}_{\mathrm{ec}}}$ vs $\mathrm{C}_{\mathrm{e}}$ & {$[25]$} \\
\hline Freundlich & $\log Q_{e c}=\frac{1}{n} \log C_{e}+\log K_{F}$ & $\log Q_{e c} v s \log C_{e}$ & [38] \\
\hline Temkin & $Q_{e c}=B \ln A+B \ln C_{e}$ & $\mathrm{Q}_{\mathrm{ec}} \mathrm{vs} \ln \mathrm{C}_{\mathrm{e}}$ & {$[40]$} \\
\hline
\end{tabular}

*Where; $Q_{t}=$ adsorption capacity at time t, $Q_{e}=$ adsorption capacity at equilibrium time, $k_{1}=$ PFO constant, $k_{2}=$ PSO constant, $\mathrm{t}=$ time interval, $\alpha=$ initial adsorption rate $\left(\mathrm{mg} / \mathrm{g}\right.$. min), $\beta=$ desorption constant, $\mathrm{b}=$ rate constant, $k_{f}$ $=$ rate coefficient value $(\mathrm{mg} / \mathrm{g} . \mathrm{min}), k_{i d}=$ diffusion rate constant $\left(\mathrm{mg} / \mathrm{g} . \mathrm{min}^{0.5}\right), \mathrm{c}=$ diffusion constant.

** $Q_{e c}=$ adsorption capacity at different concentration, $Q_{m}=$ maximum adsorption capacity, $C_{e}=$ equilibrium concentration of $\mathrm{Ni}^{2+}$ in aqueous solution, $K_{L}=$ Langmuir isotherm constant $(\mathrm{L} / \mathrm{mg}), K_{F}=$ Freundlich isotherm constant $(\mathrm{mg} / \mathrm{g})\left(\mathrm{dm}^{3} / \mathrm{g}\right)^{\mathrm{n}}, \mathrm{n}=$ adsorption intensity constant, $\mathrm{A}=$ Temkin isotherm equilibrium binding constant $(\mathrm{L} / \mathrm{g})$ and $\mathrm{B}=$ equilibrium adsorption heat constant.

Table 2 List of error functions

\begin{tabular}{|c|c|c|}
\hline Standard error & Equation & Reference \\
\hline $\begin{array}{l}\text { The Standard Error of } \\
\text { Estimate (SEE) }\end{array}$ & $S E E=\sum_{i=1}^{n}\left(Q_{e}^{e x p}-Q_{e}^{\text {model }}\right)^{2}$ & [43] \\
\hline $\begin{array}{c}\text { Coefficient of } \\
\text { Determination }\left(\mathrm{R}^{2}\right)\end{array}$ & $R^{2}=\frac{\left(Q_{e}^{\text {exp }}-\bar{Q}_{e}^{\text {model }}\right)^{2}}{\sum\left(Q_{e}^{\text {exp }}-\bar{Q}_{e}^{\text {model }}\right)^{2}+\left(Q_{e}^{\text {exp }}-Q_{e}^{\text {model }}\right)^{2}}$ & [41] \\
\hline $\begin{array}{l}\text { Normalized Standard } \\
\text { Deviation }(\Delta \mathrm{q})\end{array}$ & $\Delta \mathrm{q}(\%)=100 * \sqrt{\frac{\sum\left[\left(Q_{e}^{\text {exp }}-Q_{e}^{\text {model }} / Q_{e}^{\text {exp }}\right)^{2}\right.}{(n-1)}}$ & [44] \\
\hline
\end{tabular}

Where; $Q_{e}^{\text {exp }}=$ Experimental adsorption capacity, $Q_{e}^{\text {model }}=$ measured adsorption capacity at equilibrium calculated through model and $n=$ number of observations.

Figure 5 shows the plotted kinetic models and table 3 indicates the calculated parameters along with the $\mathrm{R}^{2}$ and SEE values of pseudo-first-order, pseudo-second-order, Elovich, power function, and intraparticle diffusion. Both the composite membranes showed $\mathrm{R}^{2}$ value of pseudo-secondorder closer to 1, revealing that PSO was more suitable than PFO for both the membranes, following PSO indicated that the adsorption process was chemisorption and exchange or share of 
electron between adsorbent and adsorbate [45]. The high value of Elovich $(\alpha)$ parameters further confirmed the chemisorption nature of membranes $[46,47]$. The high value of $c$ parameter of intraparticle diffusion indicated the adsorption process also had some boundary layer effect. The rate coefficient $\left(\mathrm{k}_{\mathrm{f}}\right)$ value as estimated from power function model was higher for Fe/PEI-AN, suggesting increased adsorption amount of $\mathrm{Ni}^{2+}$ with time.

Table 3 Calculated parameters of Kinetic models

\begin{tabular}{|c|c|c|c|}
\hline Kinetics models & Parameters & PEI-AN & Fe/PEI-AN \\
\hline \multirow{5}{*}{$\begin{array}{l}\text { Pseudo-First-Order } \\
\text { (PFO) }\end{array}$} & $\mathrm{k}_{1}$ & 0.008 & 0.007 \\
\hline & $\mathrm{Q}_{\mathrm{e}}$ & 2.445 & 3.303 \\
\hline & $\mathrm{R}^{2}$ & 0.443 & 0.289 \\
\hline & $\Delta \mathrm{q}$ & 9.899 & 8.493 \\
\hline & SEE & 0.263 & 0.343 \\
\hline \multirow{5}{*}{$\begin{array}{l}\text { Pseudo-Second-Order } \\
\text { (PSO) }\end{array}$} & $\mathrm{k}_{2}$ & 0.069 & 0.037 \\
\hline & $\mathrm{Q}_{\mathrm{e}}$ & 9.139 & 11.19 \\
\hline & $\mathrm{R}^{2}$ & 0.998 & 0.996 \\
\hline & $\Delta \mathrm{q}$ & 0.800 & 1.003 \\
\hline & SEE & 0.337 & 0.377 \\
\hline \multirow{5}{*}{ Elovich } & $\alpha$ & 10.72 & 8.369 \\
\hline & $\beta$ & 0.696 & 0.533 \\
\hline & $\mathrm{R}^{2}$ & 0.760 & 0.830 \\
\hline & $\Delta \mathrm{q}$ & 2.900 & 2.435 \\
\hline & SEE & 1.765 & 1.848 \\
\hline \multirow{5}{*}{ Power Function } & $\overline{\mathrm{k}_{\mathrm{f}}}$ & 0.300 & 0.343 \\
\hline & B & 2.632 & 2.626 \\
\hline & $\mathrm{R}^{2}$ & 0.578 & 0.641 \\
\hline & $\Delta \mathrm{q}$ & 3.077 & 2.406 \\
\hline & SEE & 0.559 & 0.561 \\
\hline \multirow{5}{*}{ Intraparticle Diffusion } & $\mathrm{K}_{\mathrm{id}}$ & 0.550 & 0.725 \\
\hline & $\mathrm{c}$ & 3.721 & 3.859 \\
\hline & $\mathrm{R}^{2}$ & 0.599 & 0.667 \\
\hline & $\Delta \mathrm{q}$ & 3.374 & 2.735 \\
\hline & SEE & 2.280 & 2.590 \\
\hline
\end{tabular}


In continuation to understand the adsorption mechanism, the $\mathrm{Ni}^{2+}$ adsorption equilibrium data of PEI-AN and Fe/PEI-AN nanofibers membranes retrieved from concentration study were analyzed by Langmuir, Freundlich and Temkin isotherm models. The equations of isotherm models for Langmuir, Freundlich and Temkin models were listed in table 1. The fitted lines of applied models and summary of calculated parameters along with error functions were shown in figure 6 and table 4.
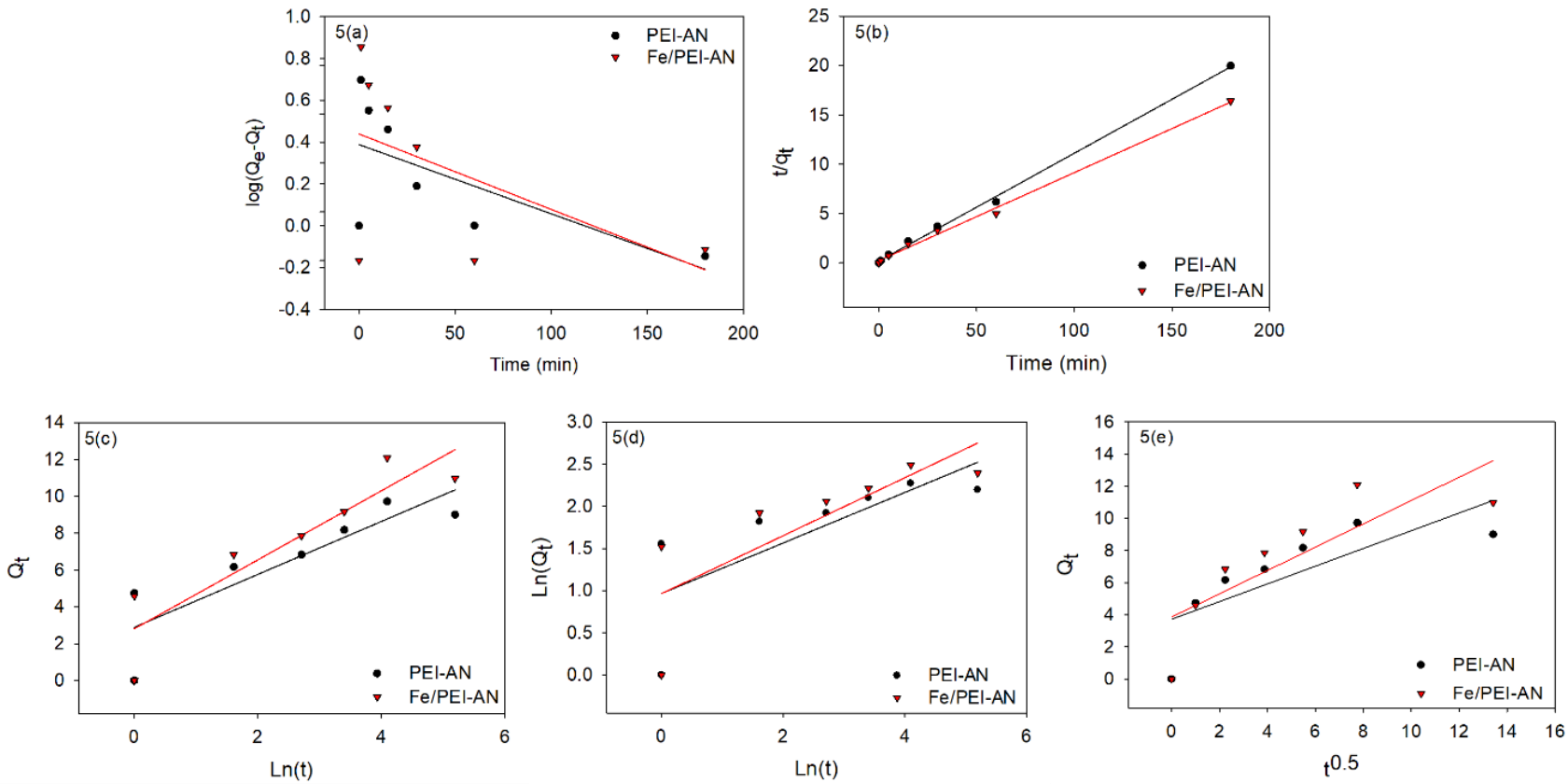

Figure 5. Plotted kinetic models (a) Pseudo First order, (b) Pseudo Second order, (c) Elovich, (d) Power Function \& Intraparticle diffusion.

According to the results of calculated parameters, $\mathrm{R}^{2}$ values of both the membranes showed the best fitting for Langmuir model $\left(\mathrm{R}^{2}>0.96\right)$ that was better than Freundlich and Temkin models, specially Fe/PEI-AN showed high value of $\mathrm{R}^{2}(\approx 0.98)$ with close $\mathrm{SEE}$ and $\Delta \mathrm{q}$ values. Temkin model values comparing with Langmuir model, suggested that the amount of adsorption had minor impact on heat. 

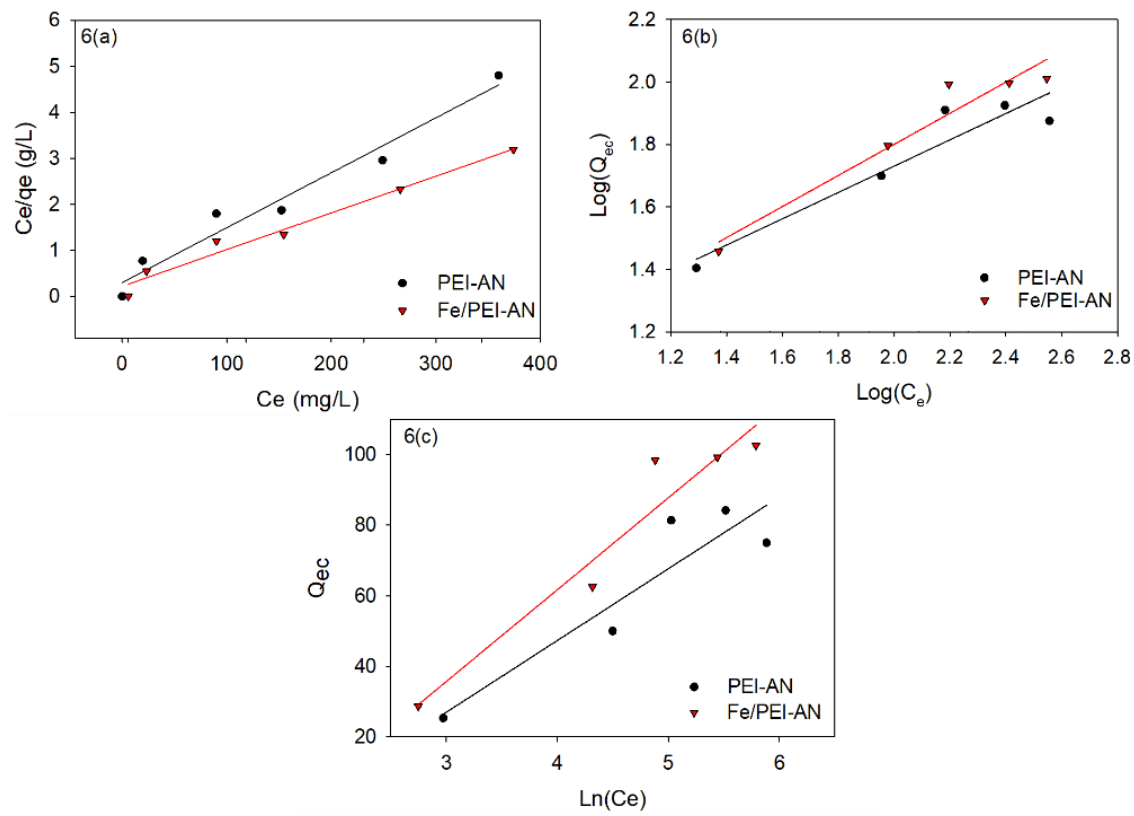

Figure 6. Plotted Isotherms models (a) Langmuir, (b) Freundlich \& (c) Temkin

Table 4. Calculated parameters of isotherm models

\begin{tabular}{|c|c|c|c|}
\hline Isotherm models & Parameters & PEI-AN & Fe/PEI-AN \\
\hline \multirow{5}{*}{ Langmuir } & $Q_{E L}^{\text {meas }}$ & 83.81 & 111.2 \\
\hline & $\mathrm{K}_{\mathrm{L}}$ & 0.039 & 0.033 \\
\hline & $\mathrm{R}^{2}$ & 0.963 & 0.975 \\
\hline & $\Delta \mathrm{q}$ & 2.565 & 0.215 \\
\hline & SEE & 0.363 & 0.206 \\
\hline \multirow{5}{*}{ Freundlich } & $\mathrm{K}_{\mathrm{F}}$ & 7.7 & 9.115 \\
\hline & $\mathrm{n}$ & 2.260 & 0.4 \\
\hline & $\mathrm{R}^{2}$ & 0.938 & 0.94 \\
\hline & $\Delta q$ & 0.823 & 1.001 \\
\hline & SEE & 2.908 & 4.377 \\
\hline \multirow{5}{*}{ Temkin } & B & 20.31 & 25.99 \\
\hline & A & 0.188 & 0.196 \\
\hline & $\mathrm{R}^{2}$ & 0.849 & 0.933 \\
\hline & $\Delta q$ & 4.086 & 4.833 \\
\hline & SEE & 11.24 & 9.589 \\
\hline
\end{tabular}

Where; $Q_{E C}^{\text {exp }}$ for PEI-AN \& Fe/PEI-AN was $84 \mathrm{mg} / \mathrm{g} \& 102 \mathrm{mg} / \mathrm{g}$, respectively. $Q_{E L}^{\text {meas }}=$ adsorption capacity calculated from Langmuir model. 


\section{Adsorption Mechanism Characterizations}

After adsorption study, characterization such as EDX with mapping, FTIR and XRD were performed on PEI-AN and Fe/PEI-AN membranes to confirm the bonding of $\mathrm{Ni}^{2+}$ ions onto composite membranes. In figure 7 and 8 EDX mapping and spectra confirmed the presence of $\mathrm{Ni}^{2+}$ onto the PEI-AN and Fe/PEI-AN membranes, respectively. Figure 9 shows the FTIR spectral curves for membranes after adsorption studies that gave the further evidence for the successful attachment of $\mathrm{Ni}^{2+}$ onto membrane. Figure 9 (a) and (b) showed the FTIR curves of membranes after adsorption and new peaks related to metal oxide vibration were found at $580^{-1} \& 670 \mathrm{~cm}^{-1}$ (curve a) and $629 \mathrm{~cm}^{-1} \& 590 \mathrm{~cm}^{-1}$ (curve b), these peaks could be assigned to Ni-OH stretching bond [48-50]. After adsorption (curve(b)) the characteristic peak at $575 \mathrm{~cm}^{-1}$ that attribute the stretching vibrations $(\mathrm{Fe}-\mathrm{O})$ produces new peak at $590 \mathrm{~cm}^{-1}$ due to the intrinsic $\mathrm{Fe}-\mathrm{O}$ interaction with $\mathrm{Ni}^{2+}[51,52]$. These results confirmed that the $\mathrm{Ni}^{2+}$ was adsorbed into the membrane's composition and interacted with magnetic particles $\left(\mathrm{Fe}_{2} \mathrm{O}_{3}\right)$. In addition, Figure 10 presents the XRD results that also suggested the $\mathrm{Ni}^{2+}$ bonding with composite membranes by presenting two new diffraction peaks at 8.9 and $9.4^{\circ}$. These peaks probably due to the reflection of adsorption layered on adsorbents after adsorption of $\mathrm{Ni}^{2+}[53]$. 


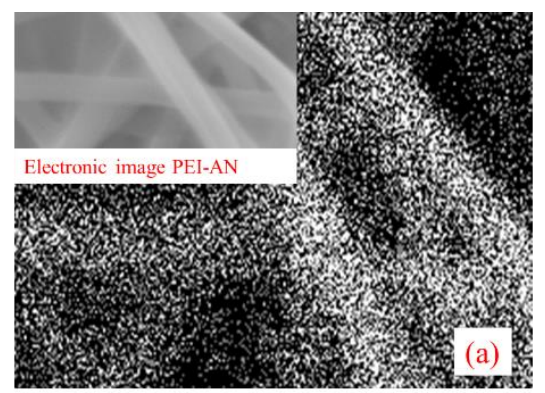

Carbon mapping

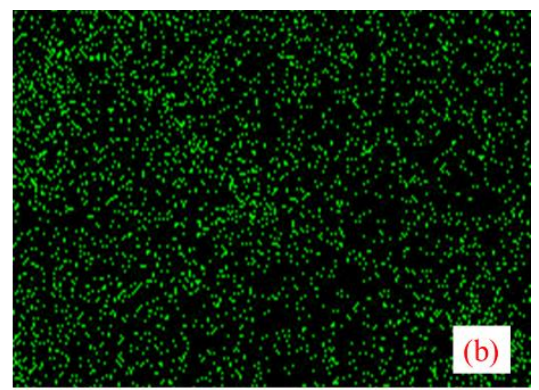

Ni mapping

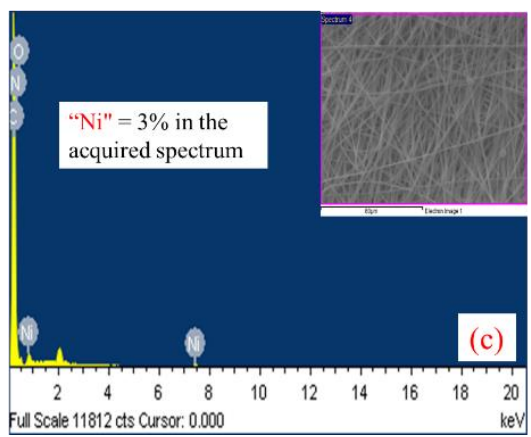

Figure 7. (a, b) EDX mapping \& (c) EDX spectra of PEI-AN after $\mathrm{Ni}^{2+}$ adsorption.

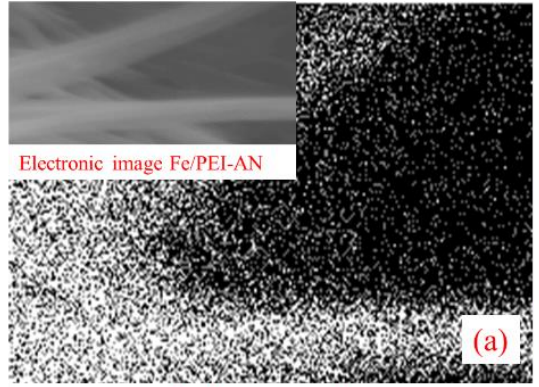

Carbon mapping

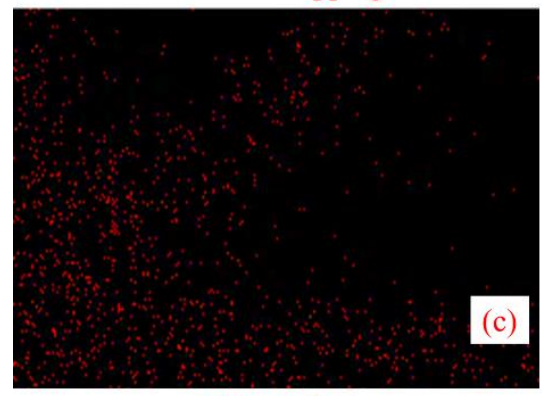

Fe mapping

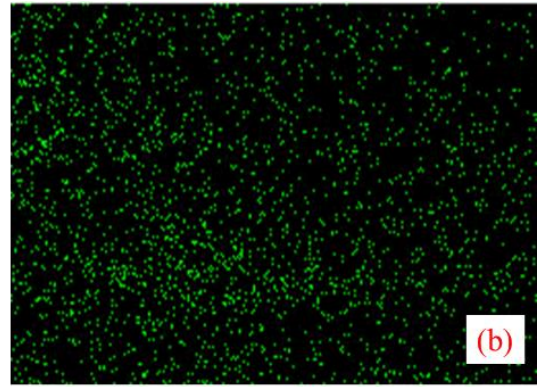

Ni mapping

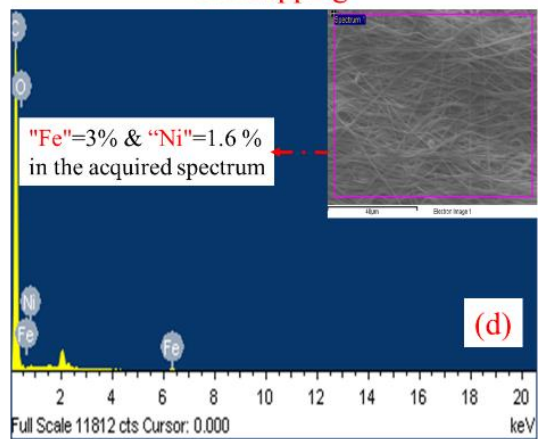

Figure 8. (a-c) EDX mapping \& (d) EDX spectra of Fe/PEI-AN after $\mathrm{Ni}^{2+}$ adsorption. 


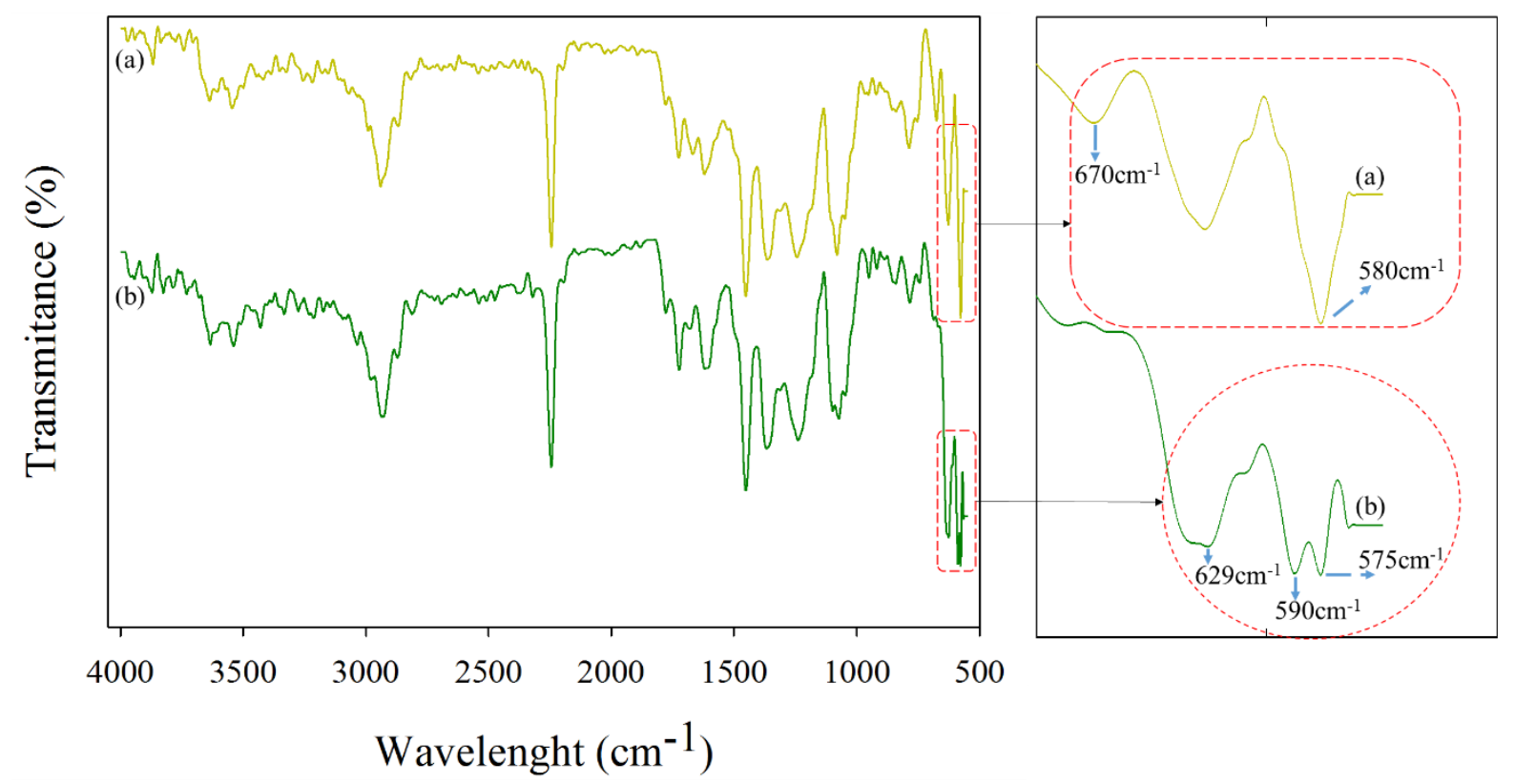

Figure 9. FTIR spectra of composite nanofibers membranes after adsorption (a) PEI-AN \& (b) Fe/PEI-AN.

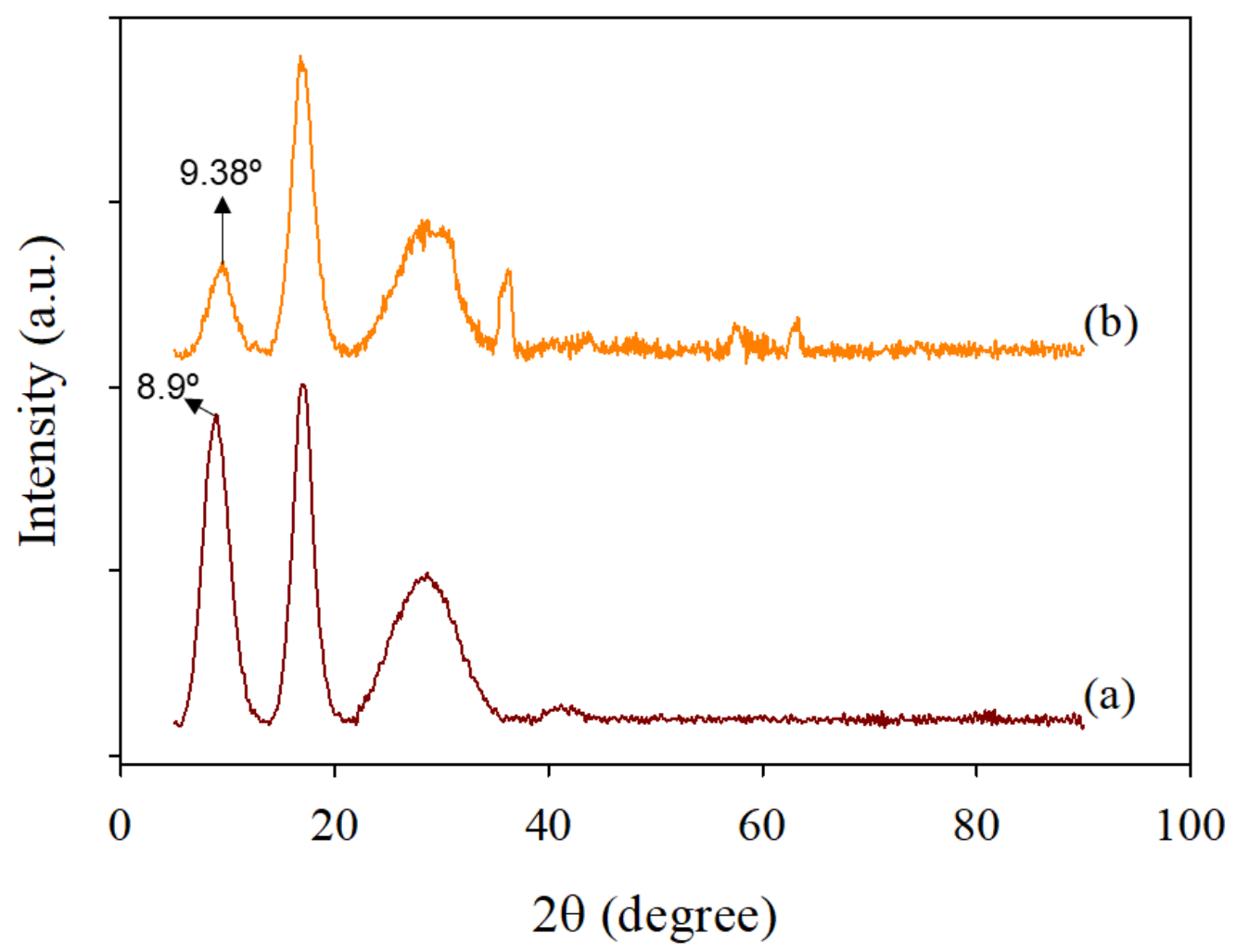

Figure 10. XRD results of composite nanofibers membranes after adsorption (a) PEI-AN \& (b) Fe/PEI-AN. 
The porous structure and surface area of nanofibers membranes were also analyzed by BET method to show the effect of porosity and surface area on adsorption capacity. The surface area, pore volume and pore average diameter recorded in table 5 that showed higher values of Fe/PEIAN comparing with PEI-AN nanofibers membranes. The higher porosity and surface area confirmed that $\mathrm{Fe} / \mathrm{PEI}-\mathrm{AN}$ had more adsorption sites for $\mathrm{Ni}^{2+}$. In addition to higher porosity and surface area, the other $\mathrm{Ni}^{2+}$ adsorption mechanism of Fe/PEI-AN composite nanofibers was shown in scheme $1 . \mathrm{Fe}_{2} \mathrm{O}_{3}$ were involved in the adsorption mechanism by ion exchange reaction between proton and $\mathrm{Ni}^{2+}$.

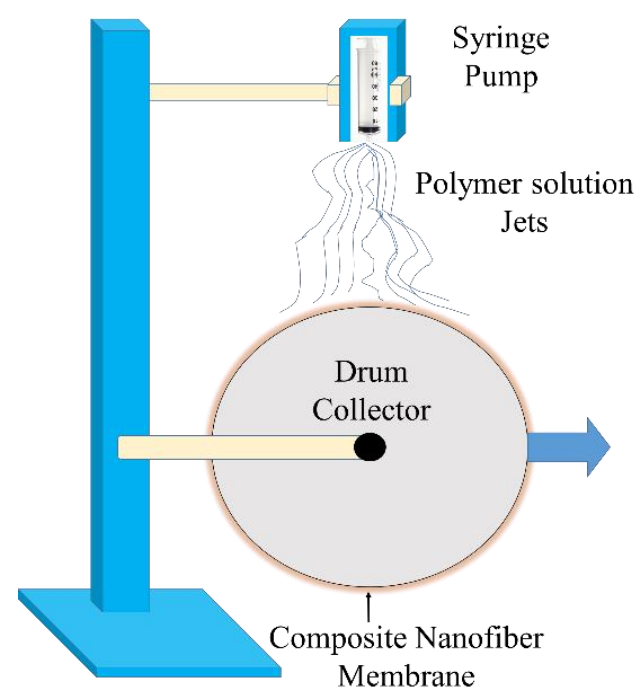

Electrospining setup \& process

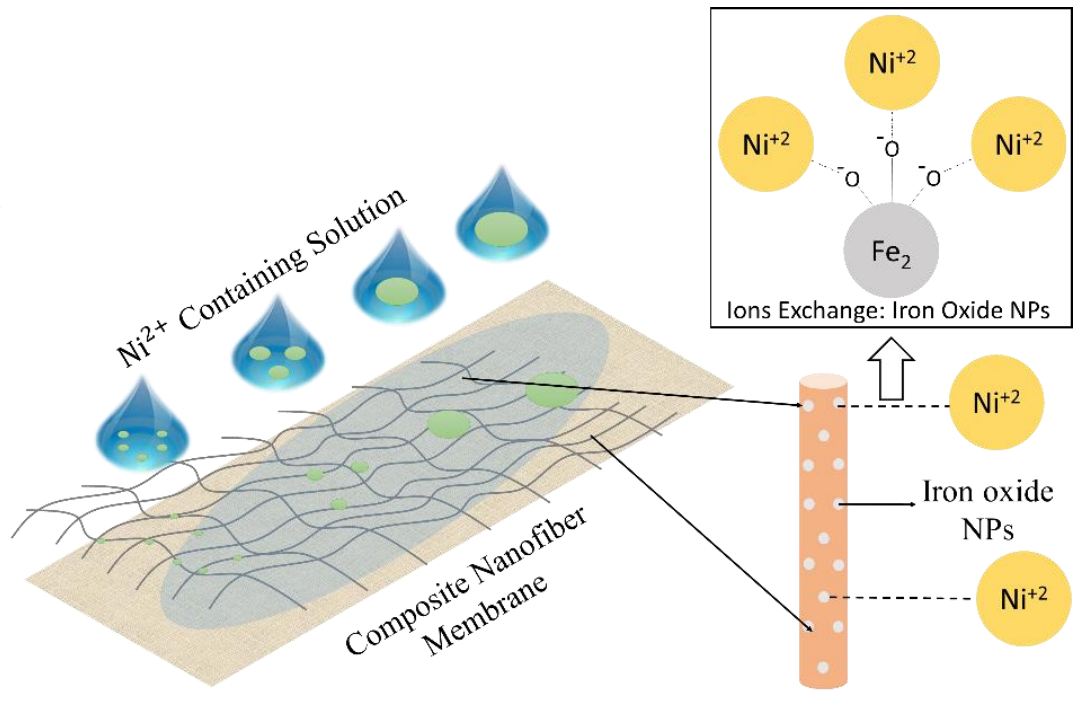

Adsorption process \& mechanism

Scheme $1 . \mathrm{Ni}^{2+}$ adsorption mechanism of FE/PEI-AN composite nanofibers membrane.

Before concluding, it is important to show how recently developed PEI-AN nanofibers membrane was used with magnetic nanoparticles without leaching out into aqueous medium and these composite nanofibers membrane successfully applied for the adsorption of metal ions with better adsorption capacity results comparing with different adsorbent listed in table 6. 
Table 5. BET test results of nanofibers adsorbents

\begin{tabular}{|c|c|c|}
\hline Samples & PEI-AN & Fe/PEI-AN \\
\hline $\operatorname{BET}\left(\mathrm{m}^{2} / \mathrm{g}\right)$ & 4.120 & 4.340 \\
\hline Pore volume $\left(\mathrm{cm}^{3} / \mathrm{g}\right)$ & 0.009 & 0.012 \\
\hline Average pore diameter (nm) & 7.800 & 9.900 \\
\hline
\end{tabular}

Table 6. Comparison of present adsorption capacity with previous studies

\begin{tabular}{|c|c|c|c|}
\hline S.no & Absorbent & Absorbent capacity & Reference \\
\hline 1 & $\begin{array}{l}\text { Polymeric nanofibers- } \\
\text { Polyvinyl pyrrolidon /chitosan/zeolite }\end{array}$ & 89.27 & [54] \\
\hline 2 & Bio sorbent - Succinylated hay & 57.70 & [55] \\
\hline 3 & Magnetic nanoadsorbent & 20.54 & [56] \\
\hline 4 & Alumina powder & 30.82 & [57] \\
\hline 5 & $\begin{array}{l}\text { Activated carbons- Doum seed } \\
\text { (Hyphaenethebaica) coat }\end{array}$ & 13.51 & [35] \\
\hline 6 & Polymeric nanofibers-PEI-AN & 84.00 & This work \\
\hline 7 & Magnetic/polymeric nanofibers - Fe/PEI-AN & 102.0 & This work \\
\hline
\end{tabular}

\section{Conclusion}

This work successfully used the electrospinning process yet again to produced novel composite nanofibers adsorbent for $\mathrm{Ni}^{2+}$ removal. The adsorption tests demonstrated that Fe/PEI-AN composite membrane showed the maximum adsorption capacity $(102 \mathrm{mg} / \mathrm{g})$ at optimized $\mathrm{pH}$ value of 8 , time interval at $60 \mathrm{~min}$ and initial concentration at $450 \mathrm{mg} / \mathrm{L}$. The collected adsorption data were analyzed with different adsorption kinetics and isotherm models, found PSO were fitted well by suggesting that the vital chemical reaction was involved during the $\mathrm{Ni}^{2+}$ adsorption process. Moreover, the adsorption data were defined well with Langmuir isotherm model that proposed monolayer adsorption were dominated during $\mathrm{Ni}^{2+}$ adsorption. The applied models and isotherms were further confirmed through the adsorption mechanism tests by EDX, FTIR, XRD and BET. 
These investigations proposed that magnetic nanoparticles in the composite nanofibers membranes enhanced ion exchange involvements and improved adsorption sites during adsorption of $\mathrm{Ni}^{2+} \mathrm{due}^{\mathrm{d}}$ to increased porosity and surface area. The developed novel composite membranes may find many applications where environmentally-friendly and nontoxic adsorbents for the removal of $\mathrm{Ni}^{2+}$ in aqueous medium are required.

Acknowledgement

The authors would like to extend their sincere appreciation to the Deanship of Scientific Research at King Saud University for funding this work through research group (RGP-1440-102). The authors have no conflict of interest to declare.

\section{Reference}

[1] A. Kumar, A. Balouch, A.A. Pathan, Abdullah, M.S. Jagirani, A.M. Mahar, M. Zubair, B. Laghari, Remediation of Nickel ion from wastewater by applying various techniques: a review, Acta Chemica Malaysia. 0 (2019). https://doi.org/10.2478/acmy-2019-0001.

[2] D. Fila, Z. Hubicki, D. Kołodyńska, Recovery of metals from waste nickel-metal hydride batteries using multifunctional Diphonix resin, Adsorption. 25 (2019) 367-382. https://doi.org/10.1007/s10450-019-00013-9.

[3] T. Shahriari, N. Mehrdadi, M. Tahmasebi, Study of Cadmium and Nickel Removal from Battery Industry Wastewater by Fe2O3 Nanoparticles, Pollution. 5 (2019). https://doi.org/10.22059/poll.2018.268193.530.

[4] Rapid removal of organic micropollutants from water by a porous $\beta$-cyclodextrin polymer | Nature, (n.d.). https://www.nature.com/articles/nature16185 (accessed February 16, 2020).

[5] S. Babel, T.A. Kurniawan, Low-cost adsorbents for heavy metals uptake from contaminated water: a review, Journal of Hazardous Materials. 97 (2003) 219-243. https://doi.org/10.1016/S0304-3894(02)00263-7.

[6] K.G. Bhattacharyya, S.S. Gupta, Adsorption of a few heavy metals on natural and modified kaolinite and montmorillonite: A review, Advances in Colloid and Interface Science. 140 (2008) 114-131. https://doi.org/10.1016/j.cis.2007.12.008.

[7] H. Beheshti, M. Irani, L. Hosseini, A. Rahimi, M. Aliabadi, Removal of Cr (VI) from aqueous solutions using chitosan/MWCNT/Fe3O4 composite nanofibers-batch and column studies, $\begin{array}{lllll}\text { Chemical Engineering } & \text { Journal. } & 284 & \text { (2016) }\end{array}$ https://doi.org/10.1016/j.cej.2015.08.158. 
[8] Abolfazl. Dastbaz, A.Reza. Keshtkar, Adsorption of Th4+, U6+, Cd2+, and Ni2+ from aqueous solution by a novel modified polyacrylonitrile composite nanofiber adsorbent prepared by electrospinning, Applied Surface Science. 293 (2014) 336-344. https://doi.org/10.1016/j.apsusc.2013.12.164.

[9] E. Ajenifuja, S.O. Alayande, O.A. Aromolaran, J.A. Ajao, E.O. Dare, T.A.M. Msagati, E.O.B. Ajayi, Equilibrium kinetics study of electrospun polystyrene and polystyrene-zeolite fibres for crude oil-water separation, Journal of Water Process Engineering. 19 (2017) 253-259. https://doi.org/10.1016/j.jwpe.2017.08.010.

[10] S. Xin, Z. Zeng, X. Zhou, W. Luo, X. Shi, Q. Wang, H. Deng, Y. Du, Recyclable Saccharomyces cerevisiae loaded nanofibrous mats with sandwich structure constructing via bio-electrospraying for heavy metal removal, Journal of Hazardous Materials. 324 (2017) 365372. https://doi.org/10.1016/j.jhazmat.2016.10.070.

[11] X. Huang, R. Wang, T. Jiao, G. Zou, F. Zhan, J. Yin, L. Zhang, J. Zhou, Q. Peng, Facile Preparation of Hierarchical AgNP-Loaded MXene/Fe3O4/Polymer Nanocomposites by Electrospinning with Enhanced Catalytic Performance for Wastewater Treatment, ACS Omega. 4 (2019) 1897-1906. https://doi.org/10.1021/acsomega.8b03615.

[12] L.R. Rad, A. Momeni, B.F. Ghazani, M. Irani, M. Mahmoudi, B. Noghreh, Removal of $\mathrm{Ni} 2+$ and $\mathrm{Cd} 2+$ ions from aqueous solutions using electrospun PVA/zeolite nanofibrous adsorbent, Chemical Engineering Journal. $256 \quad$ (2014) 119-127. https://doi.org/10.1016/j.cej.2014.06.066.

[13] M. Xia, R. Yue, P. Chen, M. Wang, T. Jiao, L. Zhang, Y. Zhao, F. Gao, Z. Wei, L. Li, Density functional theory investigation of the adsorption behaviors of $\mathrm{SO} 2$ and $\mathrm{NO} 2$ on a $\mathrm{Pt}(111)$ surface, Colloids and Surfaces A: Physicochemical and Engineering Aspects. 568 (2019) 266-270. https://doi.org/10.1016/j.colsurfa.2019.02.031.

[14] O. Dong, Z. Zhang, Z. Fu, X. Li, A Novel Composite Phase-Change Material: $\mathrm{CaCl} 2 \cdot 6 \mathrm{H} 2 \mathrm{O}+\mathrm{MgCl} 2 \cdot 6 \mathrm{H} 2 \mathrm{O}+\mathrm{NH} 4 \mathrm{Cl}$, Aust. J. Chem. 71 (2018) 416-421. https://doi.org/10.1071/CH18066.

[15] L. Jin, B. Hu, S. Kuddannaya, Y. Zhang, C. Li, Z. Wang, A three-dimensional carbon nanotube-nanofiber composite foam for selective adsorption of oils and organic liquids, Polymer Composites. 39 (2018) E271-E277. https://doi.org/10.1002/pc.24334.

[16] F.S. Al-Mubaddel, S. Haider, M.O. Aijaz, A. Haider, T. Kamal, W.A. Almasry, M. Javid, S.U.-D. Khan, Preparation of the chitosan/polyacrylonitrile semi-IPN hydrogel via glutaraldehyde vapors for the removal of Rhodamine B dye, Polym. Bull. 74 (2017) 15351551. https://doi.org/10.1007/s00289-016-1788-y.

[17] F.S. Al-Mubaddel, M.O. Aijaz, S. Haider, A. Haider, W.A. Almasry, A.S. Al-Fatesh, Synthesis of chitosan based semi-IPN hydrogels using epichlorohydrine as crosslinker to study the adsorption kinetics of Rhodamine B, Desalination and Water Treatment. 57 (2016) 1752317536. https://doi.org/10.1080/19443994.2015.1085915.

[18] M.O. Aijaz, S. Haider, F.S. Al-Mubaddel, R. Khan, A. Haider, A.A. Alghyamah, W.A. Almasry, M.S. Javed Khan, M. Javid, W. Ur Rehman, Thermal, swelling and stability kinetics of chitosan based semi-interpenetrating network hydrogels, Fibers Polym. 18 (2017) 611-618. https://doi.org/10.1007/s12221-017-6921-5.

[19] M.O. Aijaz, M.R. Karim, H.F. Alharbi, N.H. Alharthi, Novel optimised highly aligned electrospun PEI-PAN nanofibre mats with excellent wettability, Polymer. 180 (2019) 121665. https://doi.org/10.1016/j.polymer.2019.121665. 
[20] L. Zhang, M. Fang, Nanomaterials in pollution trace detection and environmental improvement, Nano Today. 5 (2010) 128-142. https://doi.org/10.1016/j.nantod.2010.03.002.

[21] M. Hua, S. Zhang, B. Pan, W. Zhang, L. Lv, Q. Zhang, Heavy metal removal from water/wastewater by nanosized metal oxides: A review, Journal of Hazardous Materials. 211212 (2012) 317-331. https://doi.org/10.1016/j.jhazmat.2011.10.016.

[22] B.I. Kharisov, H.V. Rasika Dias, O.V. Kharissova, V. Manuel Jiménez-Pérez, B. Olvera Pérez, B. Muñoz Flores, Iron-containing nanomaterials: synthesis, properties, and environmental applications, RSC Adv. 2 (2012) 9325. https://doi.org/10.1039/c2ra20812a.

[23] Z. Feng, S. Zhu, D.R. Martins de Godoi, A.C.S. Samia, D. Scherson, Adsorption of Cd ${ }^{2+}$ on Carboxyl-Terminated Superparamagnetic Iron Oxide Nanoparticles, Anal. Chem. 84 (2012) 3764-3770. https://doi.org/10.1021/ac300392k.

[24] P. Xu, G.M. Zeng, D.L. Huang, C.L. Feng, S. Hu, M.H. Zhao, C. Lai, Z. Wei, C. Huang, G.X. Xie, Z.F. Liu, Use of iron oxide nanomaterials in wastewater treatment: A review, Science of The Total Environment. $424 \quad$ (2012) 1-10. https://doi.org/10.1016/j.scitotenv.2012.02.023.

[25] C.L. Warner, W. Chouyyok, K.E. Mackie, D. Neiner, L.V. Saraf, T.C. Droubay, M.G. Warner, R.S. Addleman, Manganese Doping of Magnetic Iron Oxide Nanoparticles: Tailoring Surface Reactivity for a Regenerable Heavy Metal Sorbent, Langmuir. 28 (2012) 3931-3937. https://doi.org/10.1021/la2042235.

[26] A.E. Karatapanis, D.E. Petrakis, C.D. Stalikas, A layered magnetic iron/iron oxide nanoscavenger for the analytical enrichment of ng-L-1 concentration levels of heavy metals from water, Analytica Chimica Acta. 726 (2012) 22-27. https://doi.org/10.1016/j.aca.2012.03.018.

[27] H. Yang, Z. Tian, J. Wang, S. Yang, A magnetic resonance imaging nanosensor for Hg (II) based on thymidine-functionalized supermagnetic iron oxide nanoparticles, Sensors and Actuators B: Chemical. 161 (2012) 429-433. https://doi.org/10.1016/j.snb.2011.10.055.

[28] A.S. Teja, P.-Y. Koh, Synthesis, properties, and applications of magnetic iron oxide nanoparticles, Progress in Crystal Growth and Characterization of Materials. 55 (2009) 2245. https://doi.org/10.1016/j.pcrysgrow.2008.08.003.

[29] Magnetic cellulose-chitosan hydrogels prepared from ionic liquids as reusable adsorbent for removal of heavy metal ions - Chemical Communications (RSC Publishing), (n.d.). https://pubs.rsc.org/en/content/articlelanding/2012/cc/c2cc17795a (accessed April 3, 2020).

[30] S. Wanjale, M. Birajdar, J. Jog, R. Neppalli, V. Causin, J. Karger-Kocsis, J. Lee, P. Panzade, Surface tailored PS/TiO2 composite nanofiber membrane for copper removal from water, Journal of Colloid and Interface Science. 469 (2016) 31-37. https://doi.org/10.1016/j.jcis.2016.01.054.

[31] K.A. Gebru, C. Das, Removal of $\mathrm{Pb}$ (II) and $\mathrm{Cu}$ (II) ions from wastewater using composite electrospun cellulose acetate/titanium oxide (TiO2) adsorbent, Journal of Water Process Engineering. 16 (2017) 1-13. https://doi.org/10.1016/j.jwpe.2016.11.008.

[32] A. Razzaz, S. Ghorban, L. Hosayni, M. Irani, M. Aliabadi, Chitosan nanofibers functionalized by $\mathrm{TiO} 2$ nanoparticles for the removal of heavy metal ions, Journal of the Taiwan Institute of Chemical Engineers. 58 (2016) 333-343. https://doi.org/10.1016/j.jtice.2015.06.003.

[33] Lalhmunsiama, S.M. Lee, D. Tiwari, Manganese oxide immobilized activated carbons in the remediation of aqueous wastes contaminated with copper(II) and lead(II), Chemical Engineering Journal. 225 (2013) 128-137. https://doi.org/10.1016/j.cej.2013.03.083. 
[34] A. Afkhami, M. Saber-Tehrani, H. Bagheri, Simultaneous removal of heavy-metal ions in wastewater samples using nano-alumina modified with 2,4-dinitrophenylhydrazine, Journal of Hazardous Materials. 181 (2010) 836-844. https://doi.org/10.1016/j.jhazmat.2010.05.089.

[35] M. El-Sadaawy, O. Abdelwahab, Adsorptive removal of nickel from aqueous solutions by activated carbons from doum seed (Hyphaenethebaica) coat, Alexandria Engineering Journal. 53 (2014) 399-408. https://doi.org/10.1016/j.aej.2014.03.014.

[36] N. Tian, X. Tian, L. Ma, C. Yang, Y. Wang, Z. Wang, L. Zhang, Well-dispersed magnetic iron oxide nanocrystals on sepiolite nanofibers for arsenic removal, RSC Adv. 5 (2015) 25236-25243. https://doi.org/10.1039/C5RA01592H.

[37] K. Abbas, H. Znad, Md.R. Awual, A ligand anchored conjugate adsorbent for effective mercury(II) detection and removal from aqueous media, Chemical Engineering Journal. 334 (2018) 432-443. https://doi.org/10.1016/j.cej.2017.10.054.

[38] M.R. Karim, M.O. Aijaz, N.H. Alharth, H.F. Alharbi, F.S. Al-Mubaddel, Md.R. Awual, Composite nanofibers membranes of poly(vinyl alcohol)/chitosan for selective lead(II) and cadmium(II) ions removal from wastewater, Ecotoxicology and Environmental Safety. 169 (2019) 479-486. https://doi.org/10.1016/j.ecoenv.2018.11.049.

[39] U. Habiba, T.A. Siddique, S. Talebian, J.J.L. Lee, A. Salleh, B.C. Ang, A.M. Afifi, Effect of deacetylation on property of electrospun chitosan/PVA nanofibrous membrane and removal of methyl orange, Fe(III) and Cr(VI) ions, Carbohydrate Polymers. 177 (2017) 32-39. https://doi.org/10.1016/j.carbpol.2017.08.115.

[40] M. Ahmad, A.R.A. Usman, M.I. Rafique, M.I. Al-Wabel, Engineered biochar composites with zeolite, silica, and nano-zerovalent iron for the efficient scavenging of chlortetracycline from aqueous solutions, Environ Sci Pollut Res. 26 (2019) 15136-15152. https://doi.org/10.1007/s11356-019-04850-7.

[41] M. Ahmad, M. Ahmad, A.R.A. Usman, A.S. Al-Faraj, Y.S. Ok, Q. Hussain, A.S. Abduljabbar, M.I. Al-Wabel, An efficient phosphorus scavenging from aqueous solution using magnesiothermally modified bio-calcite, Environmental Technology. 39 (2018) 1638-1649. https://doi.org/10.1080/09593330.2017.1335349.

[42] M. Ahmad, S.S. Lee, S.-E. Oh, D. Mohan, D.H. Moon, Y.H. Lee, Y.S. Ok, Modeling adsorption kinetics of trichloroethylene onto biochars derived from soybean stover and peanut shell wastes, Environ Sci Pollut Res. 20 (2013) 8364-8373. https://doi.org/10.1007/s11356013-1676-Z.

[43] K.Y. Foo, B.H. Hameed, Insights into the modeling of adsorption isotherm systems, Chemical Engineering Journal. 156 (2010) 2-10. https://doi.org/10.1016/j.cej.2009.09.013.

[44] A.M.M. Vargas, A.L. Cazetta, M.H. Kunita, T.L. Silva, V.C. Almeida, Adsorption of methylene blue on activated carbon produced from flamboyant pods (Delonix regia): Study of adsorption isotherms and kinetic models, Chemical Engineering Journal. 168 (2011) 722-730. https://doi.org/10.1016/j.cej.2011.01.067.

[45] L. Li, Y. Li, L. Cao, C. Yang, Enhanced chromium (VI) adsorption using nanosized chitosan fibers tailored by electrospinning, Carbohydrate Polymers. 125 (2015) 206-213. https://doi.org/10.1016/j.carbpol.2015.02.037.

[46] C.W. Cheung, J.F. Porter, G. McKay, Elovich equation and modified second-order equation for sorption of cadmium ions onto bone char, Journal of Chemical Technology \& Biotechnology. $\quad 75 \quad$ (2000) 963-970. https://doi.org/10.1002/10974660(200011)75:11<963::AID-JCTB302>3.0.CO;2-Z. 
[47] G.L. Dotto, L.A.A. Pinto, Adsorption of food dyes onto chitosan: Optimization process and kinetic, Carbohydrate Polymers. $84 \quad$ (2011) 231-238. https://doi.org/10.1016/j.carbpol.2010.11.028.

[48] T. Ersam, F. Kurniawan, SYNTHESIS NICKEL HIDROXIDE BY ELECTROLYSIS AT HIGH VOLTAGE, in: 2014.

[49] P. Sivakumar, R. Ramesh, A. Ramanand, S. Ponnusamy, C. Muthamizhchelvan, Synthesis and characterization of nickel ferrite magnetic nanoparticles, Materials Research Bulletin. 46 (2011) 2208-2211. https://doi.org/10.1016/j.materresbull.2011.09.009.

[50] A. Rahdar, M. Aliahmad, Y. Azizi, NiO Nanoparticles: Synthesis and Characterization, Journal of Nanostructures. 5 (2015) 145-151. https://doi.org/10.7508/jns.2015.02.009.

[51] B. Pava-Gómez, X. Vargas-Ramírez, C. Díaz-Uribe, Physicochemical study of adsorption and photodegradation processes of methylene blue on copper-doped $\mathrm{TiO} 2$ films, Journal of Photochemistry and Photobiology A: Chemistry. $360 \quad$ (2018) 13-25. https://doi.org/10.1016/j.jphotochem.2018.04.022.

[52] K. Nakamoto, Infrared and Raman Spectra of Inorganic and Coordination Compounds, in: J.M. Chalmers, P.R. Griffiths (Eds.), Handbook of Vibrational Spectroscopy, John Wiley \& Sons, Ltd, Chichester, UK, 2006: p. s4104. https://doi.org/10.1002/0470027320.s4104.

[53] J. Miao, F.-X. Xiao, H.B. Yang, S.Y. Khoo, J. Chen, Z. Fan, Y.-Y. Hsu, H.M. Chen, H. Zhang, B. Liu, Hierarchical Ni-Mo-S nanosheets on carbon fiber cloth: A flexible electrode for efficient hydrogen generation in neutral electrolyte, Science Advances. 1 (2015) e1500259. https://doi.org/10.1126/sciadv.1500259.

[54] M. Shafiee, M.A. Abedi, S. Abbasizadeh, R.K. Sheshdeh, S.E. Mousavi, S. Shohani, Effect of zeolite hydroxyl active site distribution on adsorption of $\mathrm{Pb}$ (II) and $\mathrm{Ni}$ (II) pollutants from water system by polymeric nanofibers, Separation Science and Technology. (2019) 1-18. https://doi.org/10.1080/01496395.2019.1624572.

[55] P. Lin, J. Wu, J. Ahn, J. Lee, Adsorption characteristics of $\mathrm{Cd}$ (II) and $\mathrm{Ni}$ (II) from aqueous solution using succinylated hay, Int J Miner Metall Mater. 26 (2019) 1239-1246. https://doi.org/10.1007/s12613-019-1832-7.

[56] L.I.A. Ali, W.A.W. Ibrahima, A. Sulaiman, M.M. Sanagi, Adsorption Studies of Nickel(II) Metal Ions Uptake Using Fe3O4 Magnetic Nanoadsorbent, Jurnal Teknologi. 71 (2014). https://doi.org/10.11113/jt.v71.3864.

[57] V. Srivastava, C.H. Weng, V.K. Singh, Y.C. Sharma, Adsorption of Nickel Ions from Aqueous Solutions by Nano Alumina: Kinetic, Mass Transfer, and Equilibrium Studies, J. Chem. Eng. Data. 56 (2011) 1414-1422. https://doi.org/10.1021/je101152b. 